\title{
Endoscopic submucosal dissection of a small rectal submucosal lesion: a rare case of rectal liposarcoma
}

With the broadening of indications for colonoscopy, colonic subepithelial lesions (SELs) are more frequently detected. Their incidence is about one in 300 colonoscopies. They appear as a small bulging lesion covered with normal mucosa [1]. Liposarcoma is one of the most common soft tissue sarcomas, yet it is an extremely rare disease. Less than 20 colonic liposarcomas have been described [2]. We report here the case of a 65-year-old man referred to our endoscopy unit for endoscopic submucosal dissection (ESD) of a large laterally spreading tumor of the right colon. During the surveillance endoscopy, a 3-mm SEL was found in the middle rectum, which at the time was thought to be a small neuroendocrine tumor. The mucosa covering the SEL was normal (> Fig. 1, \ Fig. 2).

We decided to perform an ESD to do a complete removal of the suspect lesion on the hypothesis of a small neuroendocrine tumor ( $\vee$ Video 1 ). After submucosal injection, a circumferential incision was made ( $\vee$ Fig. 3 ). The double-clip traction technique was used to shorten the procedure duration (\$ Fig.4) [3]. Overall the resection lasted 14 minutes. Two clips were placed to avoid delayed bleeding. Histology revealed a complete resection of a $3-\mathrm{mm}$ well differentiated liposarcoma. The patient was referred to a specialized center. Computed tomography (CT) of the chest, abdomen, and pelvis revealed no lymph node or metastasis. The patient will be given no further treatment and will be monitored regularly by $\mathrm{CT}$ for the next 5 years.

To our knowledge, this is the first ever case report showing the endoscopic appearance of an early well-differentiated liposarcoma and its complete resection with ESD leading to complete remission. This case emphasizes that ESD is surely the most appropriate technique to remove SELs with R0 margins, as the histological diagnosis may differ a lot between SELS.
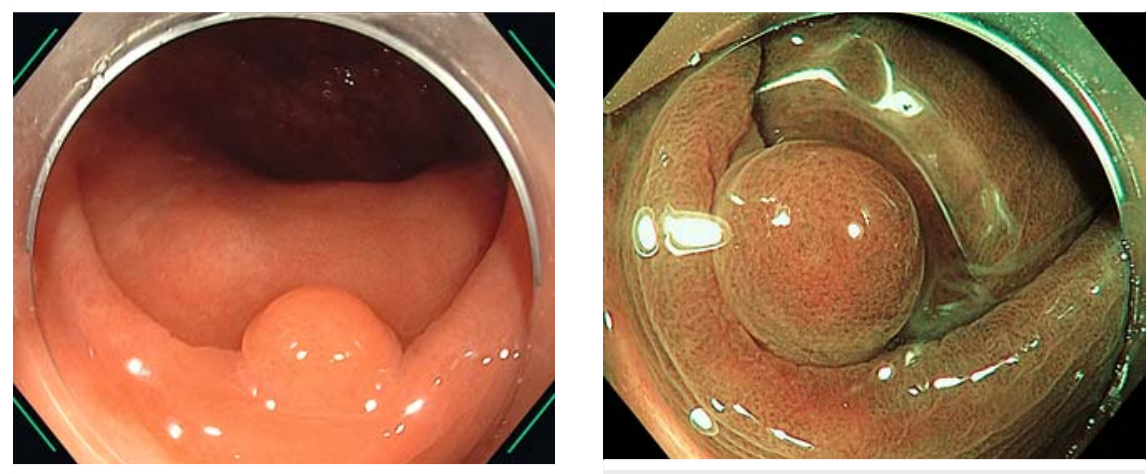

- Fig. 1 The subepithelial lesion seen in white light imaging.

- Fig. 2 The subepithelial lesion seen in narrow-band imaging.
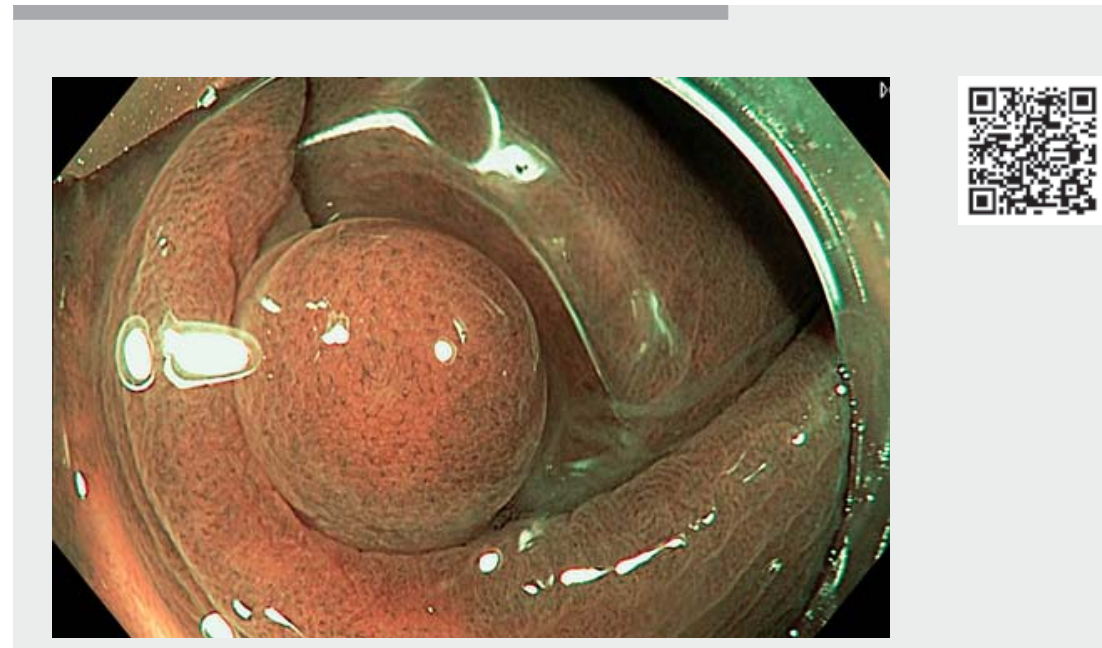

$\nabla$ Video 1 Endoscopic diagnosis and endoscopic submucosal dissection of a small rectal liposarcoma.

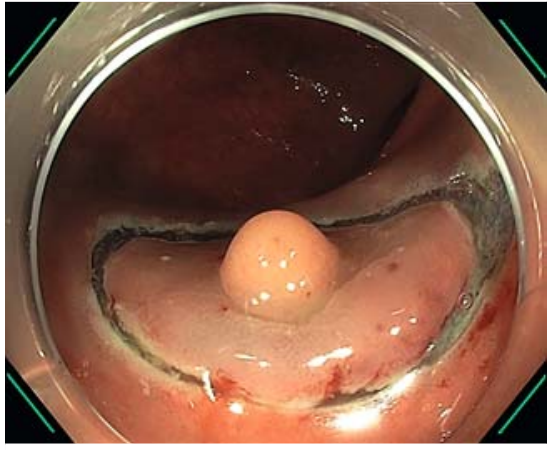

-Fig. 3 Circumferential incision after submucosal injection.

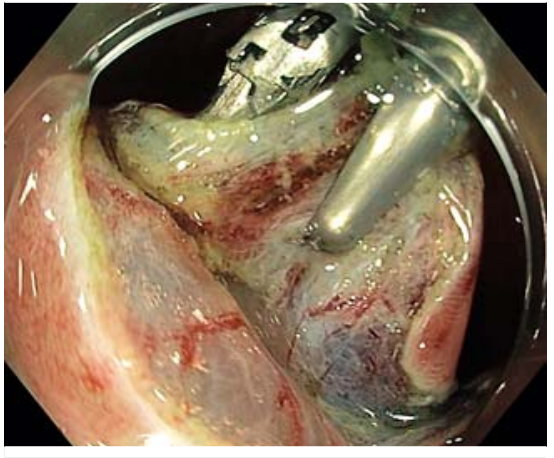

- Fig. 4 The double-clip traction technique. 


\section{Competing interests}

The authors declare that they have no conflict of interest.

The authors

Lucile Héroin ${ }^{1}$ Q Pierre Lafeuille ${ }^{2}$, Thomas Lambin $^{2}$, Pierre Mayer ${ }^{1}$, Martin Bordet ${ }^{3}$, Florian Rostain ${ }^{2}$, Mathieu Pioche ${ }^{2}$

1 Gastroenterology and Hepatology Unit, Hôpitaux Universitaires de Strasbourg, Strasbourg, France

2 Department of Endoscopy and Hepatogastroenterology, Pavillon L, Edouard Herriot Hospital, Lyon, France

3 Department of Gastroenterology, University Hospital of Rennes, Pontchaillou, Rennes, France

\section{Lucile Héroin, MD}

Gastroenterology and Hepatology Unit, Hôpitaux Universitaires de Strasbourg, 1 quai Louis Pasteur, 67000 Strasbourg, France lucileheroin@gmail.com

\section{References}

[1] Kim TO. Colorectal subepithelial lesions. Clin Endosc 2015; 48: 302-307

[2] D'Annibale M, Cosimelli M, Covello R et al. Liposarcoma of the colon presenting as an endoluminal mass. World J Surg Oncol 2009; 7: 78

[3] Bordillon P, Pioche M, Wallenhorst T et al. Double-clip traction for colonic endoscopic submucosal dissection: a multicenter study of 599 consecutive cases (with video). Gastrointest Endosc 2021; 94: 333-343
Bibliography

Endoscopy 2022; 54: E504-E505

DOI 10.1055/a-1645-1282

ISSN 0013-726X

published online 15.10 .2021

(C) 2021. Thieme. All rights reserved.

Georg Thieme Verlag KG, Rüdigerstraße 14,

70469 Stuttgart, Germany

\section{ENDOSCOPY E-VIDEOS}

https://eref.thieme.de/e-videos

回回 Endoscopy E-Videos is an open access online section. 自: reporting on interesting cases and new techniques in gastroenterological endoscopy. All papers include a high quality video and all contributions are freely accessible online. Processing charges apply (currently EUR 375), discounts and wavers acc. to HINARI are available.

This section has its own submission website at https://mc.manuscriptcentral.com/e-videos 